
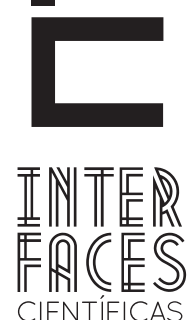

HUMANASE SOCIAIS

\title{
HISTÓRIA E LITERATURA: ENTRETEXTUALIDADES E DENÚNCIA NA NARRATIVA AMADIANA
}

Francisco Antônio Nunes Neto ${ }^{2}$

\section{RESUMO}

Este artigo discute as possíveis relações entre história e literatura, neste texto entendido como entretextualidades. Para tanto, busca estabelecer aproximações entre os tipos de narrativa do texto literário e jornalístico tomando-se como fonte e referência os textos Suor(1934) e Capitães da Areia(1937) do literato baiano Jorge Amado confrontando-os ou estabelecendo conexões entre estes dois textos com os do Jornal $A$ Tarde, todos pensados no contexto histórico da década de 1930, quando o então denominado romance-histórico, fez emergir os sujeitos do cotidiano, outrora, postos à margem das narrativas literárias.

\section{PALAVRAS-CHAVE}

História. Literatura. Representações. Cotidiano. Práticas Culturais.

\section{ABSTRACT}

This article discusses the possible relationship between history and literature, this text understood as "entretextualidades". It seeks to establish similarities between the types of narrative literary text and journalistic taking as source and reference texts Suor(1934) and Capitães da Areia(1937) the Bahia writer Jorge Amado confronting them or establishing connections between these two texts with the Jornal A Tarde, all designed in the historical context of the 1930s, when so-called historical romance did emerge daily subjects, once, relegated to the margins of literary narratives.

\section{KEYWORDS}

History. Literature. Representations. Daily. Cultural Practices. 


\section{RESUMEN}

En este artículo se analiza la posible relación entre la historia y la literatura, y este texto entendido como entre textualidades. Por lo tanto, se trata de establecer semejanzas entre los tipos de toma narrativa del texto literario y periodístico como fuente de referencia y textos Suor(1934) y Capitães da Areia(1937) del escritor Jorge Amado Bahia, confrontándolos o estableciendo conexiones entre estos dos textos con el Jornal A Tarde, todos ellos diseñados en el contexto histórico de la década de 1930, cuando el romance histórico entonces llamado, los sujetos le surgen a diario, una vez, relegados a los márgenes de narraciones literarias.

\section{PALABRAS CLAVE}

Historia. Literatura. Representaciones. Todos los Días. Las Prácticas Culturales.

\section{INTRODUÇãO}

Durante muito tempo a concepção do labor de produção de conhecimento possível aos historiadores se fez por privilegiar determinadas temáticas que acabaram por colocar no centro das abordagens uma lógica verticalizada de feitura histórica que apenas valorizava aspectos relativos aos interesses das classes ligadas aos poderes institucionais, segundo e seguindo as suas próprias vontades. Na concepção de produção de conhecimento positivista em vigor até finais da segunda década do Século XX, os tipos de fontes documentais utilizadas e as abordagens sobre elas investidas não permitiam aos historiadores tocá-los, dissecá-los, nem tampouco estabeleciam diálogos que tornassem possíveis a interação entre pesquisador e objeto de pesquisa.

$\mathrm{Na}$ área das Humanidades, as transformações processadas ao longo da década de 1920 contribuíram para o alargamento e emergência de outros olhares e interesses de pesquisa por parte dos historiadores: temas, objetos e problemas, inclusive, deve-se registrar que, até então, o texto histórico apresentava noções e visões de mundo, cujas perspectivas de abordagens mostravam-se restritamente de cunho masculizantes, relativas aos interesses deste gênero humano.
No Brasil, a Semana de Arte Moderna de 1922 ocorrida em São Paulo, os impactos proporcionados pela crise novaiorquina de outubro de 1929, juntamente com a Revolução de 1930 - que simbolizou a derrocada política das oligarquias paulista e mineira e a ascensão sulista - interferiram nas concepções de produção de conhecimento, não apenas na seara dos historiadores. Neste sentido, o texto literário despontou como releituras possíveis daquele contexto sócio-cultural, através de uma história contada ( $\mathrm{CHA}$ LHOUB e PEREIRA, 1998) em verso e prosa, por um grupo de ilustres literatos como: José Lins do Rego, Armando Fontes, José Américo de Almeida, Raquel de Queirós, Graciliano Ramos, Érico Veríssimo e Jorge Amado, num conjunto de obras literárias então denominadas Romance de 30.

Na Bahia, a vasta narrativa que compõe a obra literária de Jorge Amado, desde a sua primeira obra $O$ País do Carnaval (1931) até a Milagres dos Pássaros (1997), nos permite captar através das lentes do literato não apenas a sua concepção sobre Bahias e baianos, mas as conturbadas transformações na política e economia nacional e internacional, consideradas nas respectivas fases ou ciclos. Como demais escritores do seu tempo, Jorge Amado utilizou-se de um 
rico e variado repertório de imagens e cenas que compunham seu cotidiano, na tessitura das suas tramas, dramas e aventuras, refletidos em seus textos através da maneira como se apresenta: um (re)leitor possível dos acontecimentos históricos daquele contexto.

Há que se não esquecer que Amado escreveu numa conjuntura em que a ideologia comunista estava engatinhando, porém, a todo vapor no país. Ideologia presente na sua narrativa pelo menos no primeiro ciclo, momento em que ele atuava como militante do Partido Comunista Brasileiro. Da forma como escrevia e pelo tipo de abordagem que fazia Amado insurgiu-se como espécie de porta-voz, advogado e protetor das causas e sujeitos "populares", sem minimizá-los ou ridicularizá-los. 0 tipo de romance praticado por Jorge Amado, pelo menos os situados entre as décadas de 1930 e 1950 acabou por evidenciar problemas relativos às duras condições de sobrevivência das classes populares brasileiras, reflexo do que o autor conseguia captar/vivenciar dos/nos fatos ocorridos na política, na economia ou nas cenas do cotidiano das cidades baianas.

As andanças e experiências nas ruas, becos e vielas somadas às questões de cunho político-partidárias, os embates e querelas de cunho existenciais tão propalados pelas idéias marxistas, os impactos ainda recente dos movimentos modernistas, as vivências nos rituais sacro-africanos e outras arte-manhas, permitiram aos jovens comunistas esboçar uma compreensão de mundo calcada em suas práxis. Segundo Jorge Amado, os jovens militantes do PCB, como ele, experimentaram:

[...] profunda e intensamente a vida popular da Bahia, na saga de nossa adolescência maravilhosa: atravessávamos os dias e as noites nos cafés de literatos mas sobretudo nas feiras, nos mercados, nas festinhas juninas, nas pensões de raparigas, nos saveiros, nas moquecas na Rampa do Mercado, no sarapatel nas Sete Portas, nas casas-de-santo, nos pejis dos orixás e na luta antifascista, irredutível. (AMADO apud RISÉRIO, 2002, p. 145)
O convívio com este "outro" mundo e "outros" homens o colocou não apenas na condição de porta-voz dos então considerados "marginais" sociais, mas fez com que, através da sua obra, pudesse contribuir com as discussões e questões em torno das identidades nacionais e regionais, iniciadas no Brasil com o advento da Semana de Arte Moderna que favoreceu para o alargamento e compreensão sobre outras regiões do País como o Nordeste.

Na obra de Jorge Amado, além da Bahia ser tratada como a síntese da nação brasileira é também considerada como lugar em que os discursos sobre a modernidade ganharam uma dimensão humana, diferente das posturas modernizantes adotadas pelos até então considerados eixos econômicos do país: São Paulo, Minas Gerais e Rio de Janeiro. Neste sentido, é possível afirmar que "Amado produz [...] uma identidade-síntese do baiano que além de guardar ligações com a realidade, torna-se realidade contraposta subjetivada por seus leitores e ouvintes" (ALBUQUERQUE JR., 2001, p. 220) esboçada na musicalidade, religiosidade, valorização do ócio e de outros costumes.

A utilização de textos literários como documento-fonte de pesquisa histórica foi o mote sobre o qual se tornou possível a elaboração deste artigo, no qual, duas obras de Jorge Amado são tomadas para a realização da discussão ora apresentada sobre como as narrativas literárias podem ser tomadas como objetos de estudos pelos/as historiadores/as que buscam rastrear nas entrelinhas discursivas deste tipo de fonte os elementos de composição das narrativas, o que lhes possibilitam elaborar estudos e pesquisas no âmbito da História Social.

Muito embora as obras Suor (1934) e Capitães da Areia (1937) sejam consideradas por alguns críticos e estudiosos da obra de Jorge Amado como textos menores com caráter de panfletos políticos, aqui elas são utilizadas como (pré)texto para discutirmos entretextualidades e representações culturais, ou dizendo de outra maneira, como estas narrativas (e)(in)scritas na 
década de 1930, podem ser tomadas como referência para discutirmos as práticas cotidianas e cotidianas em Salvador no período em análise.

Assim, buscamos identificar na narrativa literária e nos textos extraídos do Jornal A Tarde de que maneira as representações elaboradas no texto literário e jornalístico estabelecem entretextualidades sobre as práticas culturais de Salvador. Neste sentido, sobre a utilização das narrativas literárias como fonte de pesquisa Heloísa Costa Milton salienta que o texto

[...] polemiza com a natureza dos fatos históricos, dando-lhe outra morada. Uma morada que alia a verdade contemplada na ficção com a verdade de corrente dos próprios fatos. Nessa medida, esse romance conta histórias da história e, muitas vezes, aquelas histórias que a própria historiografia não chegou a contar. (MILTON, 1996, p. 68)

A intenção não é submeter os textos literários a uma simples comparação com os textos dos jornais como se estes fossem capazes de uma maior aproximação com a realidade, ou o inverso. Antes, o problema que se busca evidenciar ao longo das discussões é que em larga medida não há uma discrepância entre as formas de dizer um mesmo objeto por distintas representações. Embora saibamos que literatos e jornalistas percorrem caminhos diferentes no seu processo criativo, em dado momento há uma equivalência na abordagem, uma entretextualidade.

\section{ENTRETEXTUALIDADES, CONTEXTO HISTÓRI- CO E DE PRODUÇ̄̃O DE SENTIDOS}

A Revolução de 1930 no Brasil marcou não apenas a crise política do poder oligárquico, sobretudo, paulista e mineiro, como também sinaliza tempos que vertiam para um "novo"ordenamento político, no qual a vontade de inserir o país na onda da modernização à moda européia, deu lugar a um intenso processo de industrialização, higienização e urbanização dos centros urbanos. Estas transformações conferiram às cidades uma feição mais próxima dos ideais de modernização difundidos pelas nações européias, mais precisamente, simbolizados pela cultura francesa, que desponta neste contexto como símbolo de civilitude a ser copiado. Assim, assistimos a um intenso esforço de acompanhar as transformações processadas nos centros urbanos de economia desenvolvida.

As transformações políticas então ocorridas no País com a Revolução de 1930 proporcionou o surgimento de uma abordagem literária que passou a ser identificada como Romance de 30 . 0 surgimento des-

te tipo de romance colocou em evidência não apenas o cotidiano histórico, como também deu visibilidade a personagens-sujeitos invisibilizados nas narrativas literárias. Neste tipo de literatura, o Nordeste emergiu como um cenário possível e dizível. Assim,

\begin{abstract}
[...] a emergência da análise sociológica do homem brasileiro, como uma necessidade urgente, colocada pela formação discursiva nacional-popular, dá ao romance nordestino o estatuto de uma literatura preocupada com a nação e com o povo, mestiço, pobre inculto e primitivo em suas manifestações sociais. (ALBUQUERQUE JR., 2001, p. 107)
\end{abstract}

0 romance histórico como o praticado na década de 1930, converteu-se em um texto literário engajado, logo, comprometido com as difíceis condições sociais das classes populares, problematizando o ambiente físico e social em que desenrolam-se os enredos e tramas. Desta maneira, pensar o texto literário-histórico implica perceber de que forma o literato consegue dizer sobre a história sem necessariamente utilizar 
as mesmas ferramentas (documentos) que os historiadores. Os homens das letras gozam de autonomia imaginária no seu ofício de escrita e produção de narrativas literárias, diferente dos historiadores que precisam balizar a sua escrita historiográfica através das fontes de pesquisa. 0 literato não tendo o interesse de posicionar-se como historiador, consiga dizer sobre fatos e acontecimentos ocorridos no seu entorno histórico ou não, porque conseguiu captar de maneira criativa, detalhes que possam ter passado despercebidos aos historiadores.

[...] a problemática do mundo como representação, moldado através das séries de discursos que o apreendem e o estruturam, conduz obrigatoriamente a uma reflexão sobre o modo como uma figuração desse tipo pode ser apropriada pelos leitores dos textos (ou das imagens) que dão a ver e a pensar o real. (CHARTIER, 1990, p. 24)

É dessa maneira que as narrativas literárias emergem como possibilidade de fonte para o historiador pesquisar dada realidade/época histórica, uma vez que este tipo de texto "revela facetas ocultas [redescobrindo - grifo meu] um velho universo [inventando - grifo meu] um novo. (MILTON, 1996, p. 68)

Assim, a década de 30, no Brasil, possibilitou a emergência de um novo tipo de romance que reflete as transformações processadas na política, economia, sociedade e cultura brasileira. Segundo Antonio Candido, a década de 30 no Brasil, favoreceu ao surgimento de um

[...] romance fortemente marcado de neonaturalismo e de inspiração popular, visando aos dramas contidos em aspectos característicos do país: decadência da aristocracia rural e formação do proletariado (José Lins do Rego); poesia e luta do trabalhador (Jorge Amado, Armando Fontes); êxodo rural, cangaço (José Américo de Almeida, Raquel de Queirós, Graciliano Ramos); vida difícil das cidades em rápida transformação (Érico Veríssimo). (CANDIDO, 1976, p. 123)

$\mathrm{Na}$ Bahia a conjuntura assinalada pela Revolução de 1930 influenciou na produção literária do jovem comunista Jorge Amado que, como nenhum outro, para além de ser um escritor de putas e vagabundos como problematizou Ana Paula Palamartchuk (1998), contribuiu para no processo de visibilização do modus vivendis das classes populares e desfavorecidas do território baiano, ou para usar uma expressão de Sidney Chalhoub (1990), as classes perigosas.

Dono de uma vasta produção romanesca, Jorge Amado contabiliza um total de 32 obras literárias, nas quais ele inaugura um novo "trato" sobre a Bahia e sobre os baianos, a partir da década de 30. É possível falar em "Bahias", visto que, ao longo de todas as suas narrativas, a maneira como Amado desenha o Sertão (Seara Vermelha - 1945; Teresa Batista - 1972), numa paisagem hostil, seca, representada pela caatinga, em nada se compara com a que tece sobre Salvador e Recôncavo Baiano (Suor - 1934; Jubiabá -1935; Mar Morto - 1936; Capitães da Areia - 1937; Bahia de Todos os Santos - 1945; A Morte e a Morte de Quincas Berro D'água - 1961, dentre outros), nos quais a Cidade aparece como um espaço de sociabilidade.

Devemos considerar que a entrada de Jorge Amado no Partido Comunista Brasileiro, também na década de 30 , contribuiu para que o autor na sua leitura e compreensão da sociedade desse prioridade à condição material de existência da população marginalizada, fosse em Salvador, no Sertão ou no Recôncavo. Acresça-se que o ingresso e envolvimento daqueles jovens comunistas nos cultos sacros Afro-brasileiros também exerceu forte influência não apenas nas temáticas selecionadas para a produção literária, mas a maneira como fizeram. Segundo Antonio Risério,

\footnotetext{
[...] as andanças de nossos jovens comunistas, percorrendo à vontade as ruas de Salvador e experimentando, com notável freqüência e intensidade, a vida cultural popular excepcionalmente organizada da Bahia de Todos os Santos, suas cidades, suas ilhas e seus recôncavos, acabaria por conduzi-los, de modo natural, quase que inevitável, ao cotidiano e às festas sagradas dos Terreiros de Candomblés, espaço de expressão concentrada da religiosidade de nossa gente. (RISÉRIO, 2002, p. 150)
} 
As três obras refletem uma linha de interpretação social de um Brasil, que teve em seu processo de formação cultural e histórica uma espécie de encontro sangrento entre as matrizes do povo e cultura brasileira: indígena, européia e africana, (RIBEIRO, 1995).

Não só a trajetória intelectual, mas também a produção literária de Jorge Amado refletem essas preocupações com as condições de sobrevivência social dos seus personagens. Isto denota, mais uma vez, a leitura que Amado fez do seu entorno social, uma vez que na sua narrativa, os discursos dos personagens representam uma conformação social ainda muito jovem, porém presa a um passado colonial de afirmação do poder de uma elite conservadora, prepotente e racista. Prenhe dessa atmosfera, a narrativa amadiana reflete as duras transformações ocorridas na Bahia de Todos os Santos. Em O País do Carnaval (1931), Suor (1934), Jubiabá (1935), Mar Morto (1936) e Capitães da Areia (1937), portanto, todos da década de 30, é

\section{LEITORES E LEITORAS DAS NARRATIVAS LITE- RÁRIAS DE JORGE AMADO}

No Brasil e no mundo, há um sem número de leitores/pesquisadores que utilizam a narrativa amadiana como fonte documental nas suas pesquisas históricas e sociológicas sobre a Bahia. Em face à maneira como o autor tece uma história para o lugar, colocando no centro das abordagens personagens fictício-reais, aludindo aos problemas sociais, frutos da sua experiência enquanto militante da esquerda baiana, Jorge Amado inaugura uma maneira ímpar na abordagem sobre as questões sociais, raciais, econômicas e políticas das diversas "Bahias" e baianos. Para Durval Muniz de Albuquerque Jr.:

[...] sua obra procura caracterizar o povo brasileiro, descobrir sua verdade interna, sua essência, retratar a verdade de sua visão e de sua fala. Quer configurar um possível identificar um quê de denúncia social, através da alusão aos problemas mais correntes nas condições materiais de existência da população negra e pobre de Salvador. Desse modo, enfatiza Ana Paula Palamartchuk:

[...] Escritor de putas e vagabundos? De jeito algum. Regenerador de putas e vagabundos, talvez. Jorge Amado é antes de tudo, na década de 1930, um escritor que, na medida em que radicalizava a sua opção pelo comunismo, idealizava personagens "populares" supostamente capazes de transformar a sociedade e 0 mundo. (PALAMARTCHUK, 1998, p. 354)

Portanto, além de não podermos negar a importância da narrativa amadiana como fonte de pesquisa histórica, através dos seus textos é possível flagrar elementos da história e culturas baianas na densidade representativa conferida aos seus personagens. Amado promove uma análise pormenor de uma Bahia revirada ao avesso em cada canto, ruas e vielas.

\begin{abstract}
povo e o povo para o Brasil, integrá-lo à vida nacional, à cultura do país, captando a sua originalidade. Busca desrecalcar a face popular do país, destravar a língua do povo, abrir os seus olhos e da nação para os seus problemas. Preocupa-se em fazer o país enxergar o seu povo com seus suores, cantigas, macumbas, prostituição, doenças, lutas, misérias e malandragens [...] Sua produção literária voltar-se-á para um objetivo claro: denunciar as injustiças sociais, as condições em que vivia a maioria do povo do país e propor a revolução socialista como saída para esses problemas. (ALBUQUERQUE JR., 2001, p. 213)
\end{abstract}

0 que pode ser facilmente percebido no grau de conscientização política que Amado confere aos seus personagens. Numa das passagens do texto Suor (1934): 
[...] Camaradas! É preciso acabar com as explorações. Nós somos muitos pobres, sujos, sem comida, sem casa, morando nesses quartos miseráveis. Explorados pelos ricos, que são poucos... É preciso que todos nós unamos para nos defender... É preciso que os operários se juntem em torno do partido, para acabar com as explorações. (AMADO, 1980, p. 75)

Neste texto Amado fala sobre o cotidiano de homens, mulheres e crianças que residiam no Pelourinho, a partir das suas experiências e do convívio do autor no lugar. É possível traçar um paralelo entre as condições de vida daquela gente, narradas ao longo da obra, com as descritas em outras fontes documentais, como os jornais da cidade. Como no trecho mencionado, no Jornal $A$ Tarde durante a década de 1930 diariamente o leitor deparava-se com inúmeras matérias sobre as duras condições de vida do povo pobre de Salvador.

$\mathrm{Na}$ citação anterior, Amado destaca também aspectos relacionados à moradia dos pobres que, na maioria das vezes, tinham que sobreviver amontoados nos quartos das pensões, dos velhos sobrados e cortiços. Formas de morar herdadas de um então recente passado em que a população menos favorecida, sobrevivia a duras penas, sendo que as suas moradias não possuíam menores condições de hospitabilidade. Assim, o início do século XX no Brasil também foi marcado pelas questões relativas às moradias dos pobres, dentro do contexto de modernização, ganhando lugar nas preocupações dos poderes locais, nos principais centros urbanos. Isso,

[...] provavelmente tinha a ver com a histeria do poder público contra tais habitações e seus moradores, especialmente nas primeiras administrações republicanas. Ao demolir cortiços e modificar traçados urbanos - ou seja, ao procurar mudar o sentido do desenvolvimento urbano -, os administradores da cidade atacavam também a memória histórica do movimento pela liberdade. (CHALHOUB, 1998, p. 10)

Desse modo, durante a década de 1930 encontramos nos jornais um número significativo de reportagens sobre as formas de morar. 0 texto a seguir, pu- blicado no Jornal $A$ Tarde, nos ajuda a compreender o que dissemos anteriormente:

ONDE VIVE A POBREZA: PAGAM IMPOSTOS E MORAM NA LAMA E EM TREVAS

\begin{abstract}
Succendem-se os governos municipaes e augmentam-se os tributos do povo, mas se esquecem de melhorar as condições em que vive a pobreza. Bairros e ruas, algumas bem no centro da cidade, vivem inteiramente ao abandono, sem calçamento, sem luz e a mingua de qualquer melhoramento, que só chegam para os bairros ricos. Enquanto isso, o governo escorcha com taxas pesadas e não perdoa a falta do pagamento de decima, levando á praça a choupana do pobre. Não precisamos ir longe. Bastará um passeio ali perto, á Mesquita do Tororó - um extenso lamaçal. Não custaria muito á Prefeitura correr auxílio desses seus pobres contribuintes, tentando melhorar-lhes as condições em que vivem. (Jornal A Tarde. 21 de Junho de 1934)
\end{abstract}

Em outra matéria, o leitor encontra uma radiografia das dificuldades a que estavam submetidos àqueles indivíduos que, punidos pelas suas realidades econômicas, precisavam sobreviver a ferro e fogo em casebres insalubres. Encontramos a seguinte matéria:

\section{NOS BAIRROS HUMILDES ONDE MORA A POBREZA}

Existem, infelizmente, em nossa grande cidade, dezenas de bairros proletarios, onde tudo falta, desde as cousas mais elementares e imprescindiveis... Tudo alli indica falta de conforto e hygiene. As cozinhas que, alli, existem em sua maioria são ruinas de palha e adobe, que ameaçam a todo instante as vidas dos infelizes moradores. Não há ali indice algum de hygiene; não há agua encanada, os moradores utilizam-se de fontes existentes ali perto e cuja agua nem sempre serve para beber... A Baroneza é, em rigor, uma ribanceira, cujos fundos vão dar no Dique. Ali, grande numero de mulheres se entregam á profissão de lavadeira e assim a quem chega ao local depara-se logo o pittoresco aspecto de cordas em todas as direcções, cobertas de roupas alvas e, sob ellas, as lavadeiras laboriosas, cantarolando, o dia todo, a fim de mais depressa passem as horas e chegue o momento do descanço para os seus corpos fatigados. (Jornal A Tarde. Sexta-feira, 31 de Julho de 1936)

Nestes jornais ao longo de toda a década de 1930 
encontram-se muitas informações relacionadas ao "problema" das habitações que carece de um estudo mais aprofundado, o que possivelmente contribuirá para preencher algumas lacunas nas pesquisas históricas relacionadas às questões evolutivas de um crescimento urbano desordenado, processado em Salvador. Ainda sobre o trecho da obra Suor (1934) destacado anteriormente, Jorge Amado, ao passo que politiza seus personagens, indica necessidade de construção de uma identidade classista e, neste sentido, encontramos em ambos jornais notas referentes quanto à necessidade de sindicalização dentre os operários, o que em certa medida pode refletir o início da construção de um imaginário de uma consciência em siem meio aos trabalhadores e trabalhadoras desta cidade. Assim, aquele início de organização pode ser percebido a seguir:

A SYNDICALIZAÇÃO DAS CLASSES OPERARIAS: egressa ao Rio o representante do Ministério do Trabalho,

Quanto à sua missão, o professor Joaquim Pimenta não encontrou difficuldades. Espera que, adeantados como deixou os trabalhos estejam em breve sindicalizados todas as classes trabalhistas dos Estados nordes tinos. (Jornal A Tarde. Segunda-feira, 10 de agosto de 1931)

Ainda sobre a obra Suor, percebemos que, para além de um detalhamento sobre o cotidiano daqueles agentes históricos que viviam perambulando ladeira acima e abaixo no Pelourinho, o próprio sobrado pode ser utilizado como uma metáfora ilustrativa para entendermos a configuração da formação cultural brasileira, levando-se em consideração a "coexistência" naquele micro universo de uma enorme variedade cultural. Assim,

[...] Nos 116 quartos, mais de 600 pessoas. Um mundo. Um mundo fétido, sem higiene e sem moral, com ratos, palavrões e gente. Operários, soldados, árabes de fala arrevesada, mascates, ladrões, prostitutas, costureiras, gente de todas as cores, de todos os lugares, com todos os trajes, enchiam o sobrado. (AMADO, 1980, p. 11)
A partir deste trecho, podemos buscar algumas relações entre a evidência dada pelo texto literário sobre a condição material dos moradores dos sobrados do Pelourinho na década de 1930, as transformações que se processavam no País e as informações veiculadas pelos Jornais em circulação na época no tocante ao aspecto condição social. O Pelourinho, citado em diversos textos, funciona como palco-cenário preferencial para um sem-número de personagens amadianas, todas elas nascidas a partir da existência de um grupo social, parcela da população considerada como perigosa, conceito tão largamente utilizado pelos poderes locais, que de diversas formas interferiu de maneira ostensiva no cotidiano e hábitos da população soteropolitana, por intermédio de adoção de códigos de posturas municipais.

Encontramos várias matérias que sinalizam para os aspectos relacionados à utilização do antigo centro comercial de Salvador, hoje Centro Histórico, não apenas para moradias nos sobrados e cortiços, mas como lugar em que se realizavam outros serviços, sobretudo, à noite. Desse modo, o Pelourinho passou a ser palco ou reduto dos denominados marginais sociais. Orgias e querelas envolvendo homens e mulheres e crianças, eram frequentes diuturnamente no lugar:

DE MEIA NOITE PARA O DIA A COUSA VIROU NA ZONA DO TIJOLO

\begin{abstract}
A zona da rua 28 de Setembro, onde está localizada o meretrício, deu hoje, pela madrugada o que fazer a polícia da $1^{\mathrm{a}}$ Delegacia. Desde cedo annunciava-se a pagodeira na Pensão Jardim de propriedade de Clea de Tal. Um jazz estridente fazia a delícia dos convivas, em meio a gritaria infernal. (Jornal A Tarde. Segunda-feira, 08 de janeiro de 1934)
\end{abstract}

Como já mencionamos, não foram poucos os pesquisadores, sobretudo, historiadores, sociólogos e analistas literários que adentraram pela narrativa amadiana para entender como se tornou possível ao autor tecer uma história sobre as diversas "Bahias”, criando atmosferas, inventando paisagens, sons, 
cheiros, além de uma infinidade de personagens, acrescentando ficção à realidade.

Em uma entrevista concedida ao historiador Luiz Henrique Dias Tavares na década de 1970 sobre o seu processo de criação, Jorge Amado respondeu:

[...] Por vezes uma figura, por vezes um fato, um incidente mínimo, detalhe de uma história, qualquer coisa que fere a sensibilidade e põe a imaginação a trabalhar. Aos poucos, num longo processo de elaboração interior, as figuras, os cenários vão surgindo, em certos casos delineiam-se até mesmo elementos da história. (s/d)

Quanto à infância a obra Capitães da Areia (1937) constitui-se como um excelente exercício de denúncia das condições sociais em que viviam as crianças negras e pobres em Salvador na década de 1930 em meio às transformações políticas que se processavam no Brasil/Bahia. De acordo com Martinha Geralda Roberto:

[...] a obra Capitães da Areia [...] mostra as contradições de uma sociedade que se desenvolvia a custa de graves desequilíbrios. Adere a idéia do Brasil controlado por uma minoria, voltada para seus próprios interesses, em detrimento das classes desfavorecidas e salienta o drama do menor abandonado. (ROBERTO, 1995, p. 07)

Neste sentido, o conjunto de desempregadas e desempregados, subempregadas ou subempregados, trabalhadores dos serviços informal na economia local, geralmente ligadas ao trabalho autônomo, tais como lavadeiras, costureiras, feirantes, cozinheiras, domésticas, alfaiates, artesãos, barbeiros, bedéis, biscateiros, camelôs, canoeiros, carpinas, estivadores, dentre outros, tendo que sustentar suas famílias e não tendo tempo suficiente para se dedicarem à educação e criação dos seus filhos, os deixavam perambulando pelas ruas, becos e vielas, lugares onde eles aprendiam e vivenciavam todo tipo de aventura na ordem do acaso. Alguns, nem sequer viviam com os seus pais.
Nos jornais que circulavam na década de 1930 encontramos tanto notícias aludindo ao quadro de abandono em que viviam muitas crianças em Salvador, assim como, das muitas reclamações que eram diariamente registradas. Dessa maneira, nos Jornais podemos observar dois posicionamentos quanto ao problema do menor abandonado: um em que se demonstra preocupação sobre os meninos e meninas de rua; outro, que os hostiliza. Muitas daquelas crianças criaram-se por si só, vivendo soltas pelas ruas, sujeitas às desventuras dos seus próprios destinos, a maioria, inclusive, enveredando-se nas práticas dos pequenos delitos, como pode ser verificado no fragmento a seguir:

\section{A MOLECAGEM CAMPEIA NO CENTRO DA CIDADE}

Hoje pela manhã na rua Chile, em frente às Duas Américas, quando por ali passava um omnibus com destino ao Terreiro, um moleque destes que perambulam pelas nossas ruas, pilheriou com o conductor do carro e como fosse repellido, atirou para dentro do omnibus uma grande pedra que por um milagre não attingiu o rosto de uma senhorinha. (Jornal A Tarde. Terça-feira, 04 de fevereiro de 1936)

Parece-nos que o problema da "infância ao léu", pelo menos até onde é possível verificar, não recebeu a devida atenção das autoridades competentes ao longo do tempo. Muito embora existissem instituições sem fins educativos, como a Santa Casa de Misericórdia, o seu raio de ação não conseguiu, pelo menos, conduzir a uma melhora na situação em que viviam os "malandros infantes". 0 jornal $A$ Tarde de 14 de julho de 1936, assim se referia a essa questão:

\section{O PROBLEMA DA INFANCIA ABANDONADA}

\begin{abstract}
É uma velha questão, essa, entre nós da infancia abandonada. A creança pobre, na Bahia, vive entregue a si mesma... Há na cidade uma escola de menores. É inútil comentar, que para uma população infantil tão grande como a nossa, uma só escola dessa espécie, é uma amostra bem pequena. Quantos as escolas Primárias disseminadas pelo perimetro urbano, muitas creanças cujos paes não podem vestil-as convenientemente, nem calçal-as, augmentando desse modo a vagabundagem existente nas ruas.
\end{abstract}


Capitães da Areia é uma obra de denúncia sobre a condição de vida dos menores abandonados da Cidade de Salvador. Numa breve tentativa de síntese, assinalamos que o romance histórico, para além das suas fronteiras de produção, funcionam como excelentes fontes de pesquisa histórica, muito embora os literatos não tenham intenção de escrever como historiadores. Na maioria dos casos, a produção literária de um determinado escritor, reflete o tempo vivenciado, não apenas pela narrativa como o tempo do próprio escritor, o que para Leonardo Affonso de Miranda Pereira e Sidney Chalhoub, é definido de maneira bem prática:

[...] duas observações são pertinentes neste contexto. Primeiro, a questão central não é o caráter manifestamente ficcional ou não de determinado testemunho histórico, mas a necessidade de destrinchar sempre a especificidade de cada testemunho. Assim, por exem- plo ao historiador resta descobrir e detalhar com igual afinco tanto as condições de produção de uma página em livro de atas, ou de um depoimento em processo criminal, quanto as de um conto, crônica ou outra peça literária. Cabe o mesmo interrogatório sobre as intenções dos sujeitos, sobre como este representa para si mesmo a relação entre aquilo que diz e o real, cabe desvendar aquilo que o sujeito testemunha sem ter a intenção de fazê-lo, investigar as interpretações ou leituras suscitadas pela intervenção (isto é, a obra) do autor; enfim, é preciso buscar a lógica social do texto. O bê-á-bá do ofício de historiador social é o mesmo, na análise da fonte literária, parlamentar, jornalística, jurídica, iconográfica, médica, ou seja lá o que mais. (CHALHOUB e PEREIRA, 1998, p. 8)

A citação é longa, porém absolutamente pertinente, em si tratando de uma temática que tem merecido a atenção de muitos curiosos no assunto: fazer História Social com Literatura.

\section{REFERÊNCIAS}

ALBUQUerQUE, Durval Muniz de. A invenção do Nordeste e outras artes. 2. ed., São Paulo: Cortez, 2001.

AMADO, Jorge. Capitães da Areia: Romance. Rio de Janeiro: Record, 1937.

AMADO, Jorge. Suor: Romance. 33. ed., Rio de Janeiro: Record, 1980.

CANDIDO, Antonio. Literatura e Sociedade: Estudos de Teoria e História Literária. 5. ed., São Paulo: Cia. Editora Nacional, 1976.

CHALHOUB, Sidney e PEREIRA, Leonardo Affonso de M. A História Contada. Capítulos de História Social da Literatura no Brasil. Rio de Janeiro: Nova Fronteira, 1998.

CHALHOUB, Sidney. “Classes perigosas”. Revista Trabalhadores. São Paulo-Campinas: Unicamp, 1990, nº 06.

CHARTIER, Roger. A História Cultural: entre práticas e representações. Rio de Janeiro: Bertrand Brasil, 1990.

MILTON, Heloísa Costa. In: CUNHA, Eneida L. e SOUZA, Eneida M. (Orgs.). Literatura Comparada. Ensaios. Salvador-BA: EDUFBA, 1996. 
PALAMARTCHUK, Ana Paula. Jorge Amado: um escritor de putas e vagabundos?. In: CHALHOUB, Sidney. A História Contada: Capítulos de História Social da Literatura no Brasil. Rio de Janeiro: Nova Fronteira, 1998.

RIBEIRO, Darcy. 0 povo brasileiro: a formação e o sentido do Brasil. São Paulo: Cia. das Letras, 1995.

RISÉRIO, Antonio. Adorável Comunista: história política, charme e confidências de Fernando Sant’Anna. Rio de Janeiro: Versal, 2002.

ROBERTO, Martinha Geraldo. A questão da injustiça social em Capitães da Areia. Minas Gerais: UFOP, 1995, (Monografia).

SCHWARCZ, Lília K. Moritz. Entre amigas: relações de boa vizinhança. Revista USP, Dossiê Nova História, nº. 23.

TAVARES, Luiz Henrique Dias (org.). Jorge Amado: Ensaios sobre o escritor. Salvador: EDUFBA. s/d. 